ARTÍCULO

\title{
La multidimensionalidad de una pandemia. Sociedad y Derecho en la era del post-coronavirus ${ }^{\bullet}$
}

\section{The multidimensionality of a pandemic. Society and Law in the era post-coronavirus}

\author{
Nuria Belloso Martín \\ Departamento de Filosofía del Derecho \\ Facultad de Derecho \\ Universidad de Burgos \\ https://orcid.org/0000-0001-5681-778X
}

Fecha de recepción 25/05/2020 | De aceptación: 13/10/2020 | De publicación: 28/12/2020

\section{RESUMEN.}

La multidimensionalidad de lecturas que se han abierto derivadas de los efectos del Covid-19 (filosófica, sociológica y jurídica) ofrece una oportunidad para reflexionar sobre algunas dicotomías -además de la ya clásica salud / economía- tales como riesgomiedo / alteridad, individualismo / comunidad, así como para revisar algunos de los relatos y narrativas que han intentado explicar lo que esta crisis ha supuesto y el escenario post-pandémico que podría configurarse. A partir del análisis de las dimensiones filosófica y sociológica, se pretenden sentar las bases para identificar qué cuestiones nucleares inciden en la dimensión jurídica y, a partir de ahí, apuntar algunos parámetros acerca de cómo podría repensarse el Derecho en un escenario post-coronavirus

\section{PALABRAS CLAVE.}

Covid-19, sociedad, Derecho, riesgo, miedo, alteridad, solidaridad

\section{ABSTRACT.}

The multidimensionality of readings that have been opened derived from the effects of Covid-19 (philosophical, sociological and legal) offers an opportunity to reflect on some dichotomies - in addition to the already classic health / economy - such as risk-fear / alterity, individualism / community, as well as to review some of the stories and narratives that have tried to explain what this crisis has meant and the post-pandemic scenario that could be configured. From the analysis of the philosophical and sociological dimensions, the aim is to lay the foundations to identify which nuclear issues affect the legal dimension and, from there, to point out some parameters about how Law could be rethink in a post-coronavirus scenario

\section{KEY WORDS.}

Covid-19, society, law, risk, fear, otherness, solidarity

\footnotetext{
- El presente trabajo se inscribe en el proyecto de investigación "Tool for the Prevention of frauds in European Funds with special attention to ERDF and CF", en el marco del International Research Project EUMODFRAUD (EU proposal 878513 - Hercule III 2019 Legal Training and Studies, HERCULE-2019-LT-AG, approved in 2019, 2nd November 19 de November, 2019 (EUROPEAN COMMISSION within the EU PROJECT H2020 and Hercules III Program), en el que la autora participa como miembro invitado.
} 
Sumario: 1. Introducción.- 2. Dimensión filosófica y sociológica. Hacia el relato de una sociedad del post-Covid-19: 2.1. De la sociedad del riesgo-miedo a la sociedad de la alteridad y de la confianza; 2.2. De la sociedad individualista a la sociedad de comunidad.- 3. Dimensión jurídica. La conveniencia de (re)pensar filosóficamente el Derecho en un escenario post-Covid19: 3.1. La relación con el futuro; 3.2. Reconstrucción de la alteridad; 3.3. Replanteamiento de la tridimensionalidad de la sociedad; 3.4. (Re)pensar el Derecho.- 4. Reflexiones finales. A propósito de una filosofía jurídica del post- virus

\section{Introducción}

Los filósofos suelen caracterizarse más por hacer preguntas que por ofrecer respuestas taxativas sobre los problemas que surgen. Esta pandemia ha abierto un sinfín de interrogantes ya que, además de su incidencia en el ámbito sanitario, sus efectos se han proyectado sobre otros tales como, el político, el económico, el fillosófico, el sociológico y también el jurídico, llegando a adquirir una proyección multidimensional. Si bien sobre esta crisis ha primado el debate constitucionalista, ${ }^{1}$ ello no ha oscurecido ni mermado la relevancia de los demás enfoques y perspectivas de estudio, como es el iusfilosófico.

Sin querer incurrir en planteamientos y discusiones vanas, en los moldes en los que a veces se sitúa injustamente a los filósofos, ${ }^{2}$ cabe preguntarse si la filosofía política y jurídica está dotada de las herramientas adecuadas para ofrecer las principales claves de un fenómeno tan inédito como es el pandémico. ${ }^{3}$ Es suficientemente conocido que, epidemias, Guerras Mundiales y otros diversos acontecimientos, a lo largo de la historia reciente, han supuesto la pérdida de miles de vidas humanas. En esas situaciones, los filósofos se han visto interpelados por la dolorosa realidad que hayan tenido que vivir, en su respectiva época, refelxionando y sacando a la luz las ideas que subyacen en la toma de decisiones que se adoptan en situaciones excepcionales.

El presente trabajo pretende ofrecer algunas reflexiones al hilo de los efectos derivados del SARS Cov 2 más comúnmente denominado Covid-19 - declarado por la OMS como pandemia - y ello, a la luz de las perspectivas de la filosofía político-jurídica y social con la finalidad de analizar qué incidencia ha

\footnotetext{
${ }^{1}$ La perspectiva constitucionalista no será objeto de análisis en este trabajo, si bien ha sido la que, después de la relativa a la emergencia sanitaria, ha prevalecido en los debates, planteándose si debía de haberse declarado un estado de alarma o de excepción, o si la aplicación del estado de alarma ha supuesto una limitación o una suspensión de derechos fundamentales. Vid. AA. VV. El Cronista del Estado Social y Democrático de Derecho. Coronavirus ... y otros problemas, $\mathrm{n}^{\circ}$. 86-87 Marzo-abril 2020. www.elcronista.es > El-Cronista-número-8687-Coronavirus

2 Vid. DE LOS RÍOS, I., "Mórbida crisis, débil gobierno: Aristóteles y la estrategia del náufrago”, en Di Luciana, C. y Velasco, G. (Compiladores), Normalidad de la crisis/crisis de la normalidad, Buenos Aires-Madrid, Katz Editores, 2012, pp.13-28.

${ }^{3}$ LARIGUET, G., "El coronavirus: miniaturas filosóficas" (3 abril, 2020) Redacción La Tinta https://latinta.com.ar/2020/04/coronavirusfilosofia/
} 
tenido en el concepto del Derecho, y la necesidad de pensar a qué desafíos debe dar respuesta el Derecho en un escenario (post)pandémico. La multidimensionalidad de enfoques posibles, junto con las cuestiones e interrogantes de todo orden derivadas de una situación de emergencia derivada de la pandemia, toman como punto de partida diversas concepciones ideológicas que, a la postre, acaban incidiendo en las respectivas visiones sobre el tema.

Desde quienes sustentaban, en perspectiva conspiratoria, que tal alarma por el virus no era más que un pretexto por parte de los Gobiernos para someter a los ciudadanos a estados de emergencia con medidas restrictivas de derechos y con sistemas tecnológicos de vigilancia y control, ${ }^{4}$ a aquéllos otros que han puesto el acento en cuestiones de justicia social con relación al derecho de acceso a la salud y a las vacunas -cuando las haya-; o incluso a poner el acento en la justicia distributiva, a modo de "elección estratégica" o "dilemas trágicos", en aquellos casos en que no se dispusiera de suficientes medios para atender a todos los pacientes que requerían atención y medios sanitarios. Desde quienes consideran que esta pandemia es un síntoma del fin del capitalismo, a quiénes interpretan que refleja una reacción con la que el planeta nos castiga por el escaso respeto al medioambiente y la inacción contra el cambio climático. Desde interpretarlo como un castigo por ocultos experimentos de laboratorio, hasta voces que se alzan considerándolo como un efecto más de la indeseable globalización. Desde aquéllos que con la pandemia ven cumplidos sus vaticinios de visiones catastrofistas con un próximo colapso del mundo, hasta aquellos otros que, con enfoques más esperanzadores lo interpretan como una oportunidad para la recuperación de valores como la solidaridad. "Sociedad inmunológica", "doctrina del shock", "política de caos", "regreso a la sociedad disciplinaria", y otros diversos rótulos, constituyen un reflejo de la variedad de lecturas en las que se proyectan las muchas inquietudes que esta pandemia ha suscitado. ${ }^{5}$

A partir de esas diversas interpretaciones, se pretende reflexionar acerca de qué transformación podrá suponer esta pandemia en el ámbito social y, principalmente, si se reflejará en una renovada forma de pensar y entender el Derecho. Porque también puede suceder que sólo sea un mero paréntesis y, una vez se recobre la normalidad -ya no se sabe si la "anterior" o la "nueva"-, todo vuelva a ser como antes.

\footnotetext{
4 AGAMBEN, G., "The Invention of an Epidemic", European Jornal of Pshicoanlysis (Publicado en Italia en Quodlibet, https://www.quodlibet.it/giorgio-agamben-l-invenzione-di-un-epidemia) $\quad(26 \quad$ Febrero $\quad 2020)$. https://www.journalpsychoanalysis.eu/coronavirus-and-philosophers/

${ }^{5}$ Se puede recordar aquí el viejo problema de la teodicea: ¿cómo un Dios bueno y todopoderoso pudo permitir tanto mal? Y los debates entre Voltaire (Poema sobre el desastre de Lisboa, 1755), y Rousseau (Carta sobre la Providencia,1756), acerca de la existencia de la Providencia divina y su papel como benefactora universal.
} 
En nuestra opinión, se han abierto unos desafíos de tal calado que, en cuanto a la Teoría del Derecho se refiere, resultan necesarios unos enfoques renovados, acordes a las nuevas necesidades sociales, sin que ello suponga mermar ni un ápice los logros conseguidos hasta ahora en cuanto Estado democrático de Derecho.

\section{Dimensión filosófica y sociológica. Hacia el relato de una sociedad del post-Covid-19}

Entre los meses de febrero y abril de este año 2020, filósofos de la política y sociólogos, ofrecieron sus respectivos diagnósticos sobre la pandemia en diversos artículos publicados en blog, sites web o prensa -medios todos ellos que permitían una publicación inmediata porque las reflexiones se sucedían cada día-. En la búsqueda de una narrativa filosófico-política explicativa, ya sea del origen de la pandemia o de los efectos que derivarán de la misma, se incluyen interpretaciones a partir del binomio capitalismo-socialismo (Zizek, Harvey, Davis), ${ }^{6}$ posiciones que confían en que la pandemia desembocará en un empoderamiento ciudadano y en una solidaridad mundial (Noah Harari), ${ }^{7}$ y teorías que vaticinan la colapsología (Latour, Citton y Rasmi). ${ }^{8}$ Son relatos que aportan justificaciones filosóficas de una misma realidad en distintas claves: tesis conspiratorias, tesis inmunológicas, tesis negacionistas, tesis catastrofistas, teorías esperanzadoras, construcciones en línea ecológica, y otras, ${ }^{9}$ y que ponen de

\footnotetext{
${ }^{6}$ Exponen una narrativa de crítica a la globalización y al capitalismo, apuntando que la emergencia sanitaria ha puesto de manifiesto, una vez más, la desigualdad y la necesidad de establecer renovados parámetros de justicia social, advirtiendo además de que deberían buscarse otras soluciones diferentes a la crisis de 2008. Vid. ZIZEK, S., "El coronavirus es un golpe al capitalismo a lo 'Kill Bill' que podría reinventar el comunismo", Russia Today, (29 feb 2020). https://actualidad.rt.com/actualidad/344511-slavoj-zizek-coronavirus-golpe-capitalismo-killbill-reinventar-comunismo; ŽIŽEK, S., PANDEMIC!COVID-19 Shakes the world, OR/Books, 2020; HARVEY, D., "Anti-Capitalist Politics in the Time of COVID-19" (19 marzo 2020; revisado 22 marzo 2020). https://davidharvey.org/2020/03/anti-capitalist-politics-inthe-time-of-covid-19/; DAVIS, M., "COVID-19: el monstruo llama a la puerta", trad. de Viento Sur, (13/03/2020). https://vientosur.info/spip.php?article15712

${ }^{7}$ HARARI, Y. N., "Yuval Harari: El mundo después del coronavirus”, Diario La Vanguardia (05.04.2020) (“The wordl after coronavirus", Financial Times, trad. de Juan Gabriel López Guix. https://www.lavanguardia.com/internacional/20200405/48285133216/yuval-hararimundo-despues-coronavirus.html; KLEIN, N., La doctrina del shock. El auge del capitalismo del desastre, trad. de Isabel Fuentes García; Albino Santos Mosquera y Remedios Diéguez Diéguez, Ed. Booket, 2007; también, de la misma autora, "Coronavirus Is the Perfect Disaster for 'Disaster Capitalism'”. https://www.vice.com/en_us/article/5dmqyk/naomi-klein-interview-on-coronavirus-and-disaster-capitalismshock-doctrine

${ }^{8}$ La colapsología engloba todas las tesis que desarrollan la idea de que la forma de vida industrial occidental y su corolario, el extractivismo minero y la agroindustria, exceden ampliamente las capacidades del planeta. De esta contradicción entre el estilo de vida y el modo de producción, ya resulta una serie de cataclismos que son naturales sólo de nombre y donde debemos ver el comienzo de un colapso de la civilización más general. Vid. CITTON, Y. y RASMI, J., Générations collapsonautes. Naviguer par temps d'effondrement. Seuil, 2020. Latour defiende que, después de la pandemia, no debemos volver al estado anterior de superproducción y consumismo y que, por ello, nada debería ser como antes. LATOUR, B., "Imaginer les gestes-barrières contre le retour à la production d'avant-crise", AOC, (30 Marzo 2020). https://aoc.media/opinion/2020/03/29/imaginer-les-gestes-barrieres-contre-le-retour-a-la-production-davant-crise/
}

9 IMBERT, N., “COVID- 19. 10 propuestas para pueblos y territorios más resilientes”, Actualidad Jurídica Ambiental, n. 100, Sección "Comentarios" (6 Abril 2020); también, vid. RODRÍGUEZ, P., "Un debate con Giorgio Agamben, Slavoj Zizek, Byung Chul-Han, Markus Gabriel y Yuval Harari. Los intelectuales y los lugares comunes ante el coronavirus", Diario El País (08.04.2020). https://www.pagina12.com.ar/258063-los-intelectuales-y-los-lugares-comunes-ante-el-coronavirus 
manifiesto la diversidad de enfoques filosóficos sobre el Covid-19. Todas estas narrativas se proyectan en unas tendencias sociológicas, como exponentes de tendencias orientadoras de configuración de las sociedades, las cuales, a su vez, orientan el ser y el deber ser del Derecho.

La literatura ha tratado el escenario de epidemias y plagas contagiosas que se extienden invisiblemente, tales como el cólera, la peste o la gripe, que dejaron miles de víctimas y que configuran un escenario que permite examinar la naturaleza humana a la luz de la filosofía y de la sociología. De Boccaccio a Saramago, la bibliografía sobre plagas víricas es extensa. El mensaje esperanzador de que esas situaciones catastróficas suponen una catarsis para el ser humano parece impregnar la mayoría de los relatos sobre las pandemias, aunque la polaridad de situaciones y de interpretaciones suele estar presente. Aquí se examinarán dos de estas tendencias como exponentes del dualismo interpretativo que puede hacerse con relación a la transformación que pueda experimentar una sociedad post-pandémica.

\subsection{De la sociedad del riesgo-miedo a la sociedad de la alteridad y de la confianza}

Las epidemias tienen la virtualidad de dejar al ser humano desprovisto de sus mecanismos ordinarios de defensa, con los que se siente seguro, entrando en una fase de temor ante lo desconocido. Miedo a la enfermedad, temor a la muerte, inseguridad ante los cambios, incertidumbre ante el futuro, todo ello podría encajar en el modelo de sociedad, conceptuada por Beck, como "sociedad del riesgo". ${ }^{10}$ El Covid19 ha hecho resurgir el concepto de riesgo. Y no porque hubiera desaparecido anteriormente, sino porque era de carácter marginal, como concepto que trabajan exclusivamente algunos especialistas. El riesgo se puede definir, siguiendo a De Giorgi, como una modalidad de relación con el futuro. Es una forma de determinación de las indeterminaciones según la diferencia de probable / improbable. ${ }^{11}$ El riesgo no debe de entenderse como un concepto opuesto al de seguridad necesariamente. El riesgo adopta diferente significado si lo construimos a partir de la distinción riesgo / seguridad, o de la distinción riesgo / peligro.

Pero la crisis que ha suscitado el COVID-19, ha provocado que el modelo de la sociedad del riesgo se haya visto ampliado a una sociedad del miedo. Ya no se trata sólo de un potencial peligro que se cierne

\footnotetext{
${ }^{10}$ En 1986, Ulrich Beck publicó su obra La sociedad del riesgo, iniciándose así un conjunto de estudios que inciden en aspectos sociológicos y filosóficos sobre la cuestión. El concepto clave que acompaña a las reflexiones de Beck, es el de las consecuencias no esperadas de la acción. Así, cada innovación científico-técnica, no sólo debe ser vista desde el ángulo de sus metas manifiestas, sino de sus consecuencias latentes. BECK, U., La sociedad del riesgo. Hacia una nueva modernidad, Barcelona, Paidós, 2006. Por su parte, Luhmann -a partir de las críticas a Beck- publicó en 1991 una Sociología del riesgo, siendo estas dos obras una referencia en la temática.
}

${ }^{11}$ DE GIORGI, R., Direito, Democracia e Risco: vínculos com o futuro, Porto Alegre, Sergio Antonio Fabris Editor, 1998. 
amenazante sobre el futuro, sino que ese peligro se ha concretado en el presente -aunque sepamos muy poco sobre esa amenaza (el virus)-. Estamos ante un "no saber", un caminar en la oscuridad -como en el Ensayo sobre la ceguera, de Saramago- y se ha tenido que combatir esta enfermedad al mismo tiempo que se la investigaba. El miedo no es simplemente una emoción molesta, sino que puede ir seguido de unas acciones precipitadas, poco racionales y que desencadenen consecuencias no esperadas. Por ejemplo, el miedo facilita mecanismos de manipulación política que después no son fáciles de hacer retroceder. El modo en cómo se responde a un miedo (la pandemia) está influido por la manera en cómo se percibe la amenaza, por la sensación de inseguridad existencial, y por la capacidad de dar significado a lo imprevisto.

El temor, la sospecha, y el miedo, tienen la virtualidad de que consiguen reacciones en sentido contrario y que pueden llegar a suponer una fractura de las estructuras sociales. Desde quienes continuarán en el "distanciamiento social" (preferencia por las relaciones digitales sobre las humanas, encumbrando la relevancia de un Derecho que regule las nuevas tecnologías, posiciones proclives a defender que los problemas de los "Otros" no les afectan), a quienes intentarán recuperar a la mayor brevedad los vínculos sociales, impulsando la confianza en el Otro, impulsandoel diseño de un horizonte de alteridad y de solidaridad.

\subsection{De la sociedad individualista a la sociedad de comunidad}

Una de las consecuencias de las epidemias es la distinción entre, aquéllos que están libres de contagio (por rasgos inmunológicos u otras circunstancias), y la de los contagiados. La tentación de alejarse del potencial contagiante, se convierte en una invitación a salir de la zona apestada, a salvarse de algún modo, donde el aislamiento social es una de las medidas preventivas para no contagiarse. Se exigen sacrificios individuales por un bien individual - como es la salud de cada ciudadano- y también por un bien colectivo -como es la salud pública, la de toda la sociedad-. Esta pandemia ha permitido tomar conciencia de que el interés individual no puede desligarse del colectivo. La responsabilidad y la autonomía no pueden quedar tan distantes del Otro, de un Otro que no está tan lejos, sino al lado.

Ese dualismo entre una sociedad individualista-liberal, y otra autoritaria-comunitaria, es la que el

filósofo surcoreano, afincado en Berlín, Byung-Chul Han, ha tomado como referencia para analizar los 
distintos modos con que Asia y Europa se han enfrentado a la pandemia, ${ }^{12}$ concluyendo que los países asiáticos están gestionando mejor esta crisis que Occidente. La tradición confucionista engendra una mentalidad autoritaria, una mayor obediencia, más confianza en el Estado y un primado de la colectividad sobre el individuo. Han no confía en que el virus vaya a aportar una mirada hacia el Otro, ni que vaya a derivar en un incremento de solidaridad. Por el contrario, advierte de que se incrementa el individualismo: "El virus nos aísla e individualiza. No genera ningún sentimiento colectivo fuerte (...). ${ }^{13}$

\section{Dimensión jurídica. La conveniencia de (re)pensar filosóficamente el Derecho en un escenario} post-Covid-19

Toda crisis pone de manifiesto las excelencias y los defectos de un sistema. En el ámbito jurídico, a partir de la llegada del virus, han emergido cuestiones nucleares que, o bien estaban latentes, o bien se las estaba posponiendo para otro momento más oportuno, a la vez que también han surgido otras nuevas, a las que hay dar respuesta. La relación con el futuro, la reconstrucción de la alteridad, la recuperación de la corporeidad, y el replanteamiento de la tridimensionalidad de la sociedad, todo ello ayuda a (re)pensar el Derecho, un Derecho que exige una renovación en algunos de sus parámetros. También se han incorporado al sistema jurídico conceptos nuevos para las sociedades occidentales, tales como confinamiento, distanciamiento social, nueva normalidad, cierre perimetral y otros, categorías conceptuales que seguramente se irán ampliando. A todo ello se hará referencia seguidamente.

\subsection{La relación con el futuro.}

Las categorías de tiempo y espacio han adquirido protagonismo en la medida en que, la planificación de las acciones, tiene como referencia el futuro. ${ }^{14} \mathrm{El}$ tiempo futuro ideal se presenta como una "vuelta a la nueva normalidad" -terminología contradictoria en sí misma porque lo que es nuevo, no

\footnotetext{
${ }^{12}$ En su obra, Sociedad del cansancio, de 2017, el autor ofrecía un relato de sociedad inmunológica según la cual, la sociedad occidental está sufriendo un silencioso cambio de paradigma, un exceso de positividad que está conduciendo a una sociedad del cansancio. Vid. HAN, B. Ch., Sociedad del cansancio, trad. de Arantzatzu Saratxaga Arregi, 2a ed., Barcelona, Herder Editorial, 2017. A su juicio, el comienzo del siglo XXI, desde un punto de vista patológico, no sería ni bacterial ni viral, sino neuronal. Su diagnóstico no resultó acertado ya que esta pandemia ha demostrado que no estamos inmunizados frente a los virus. HAN, B.Ch., "Entrevista", trad. de Alberto Ciria, Madrid, Diario El País (22 Marzo 2020). https://elpais.com/ideas/2020-03-21/la-emergencia-viral-y-el-mundo-de-manana-byung-chul-han-elfilosofo-surcoreano-que-piensa-desde-berlin.html

${ }^{13}$ Ibidem

${ }^{14} \mathrm{El}$ futuro constituye una categoría que impregna la vida del ser humano: desde la democracia a la política, desde el medioambiente a la economía, el futuro las dota de un sentido particular. Vid. INNERARITY, D. Una teoría de la democracia compleja. Gobernar en el siglo XXI, Barcelona, Galaxia Gutenberg, 2020, y también, del mismo autor, vid. Pandemocracia. Una filosofia de la crisis del coronavirus, Galaxia Gutenberg, 2020.
} 
puede ser normal- planteándose como reto, lograr unas condiciones (libertades, derechos) que eran los que ya se tenían en el pasado -a modo del "eterno retorno" borgiano-. ${ }^{15}$ Por otro lado, el espacio ha cobrado mayor protagonismo, el distanciamiento social, el alejarnos del otro, selección de itinerarios dnde no estén los Otros, cuadrantes que marcan dónde situarnos, corredores que habrá que seguir obligatoriamente, nuevos protocolos. Toda una nueva disciplina que controlará la libertad de movimientos que antes teníamos.

La pandemia nos ha colocado ante el interrogante continuo de "qué pasará mañana", "cuándo se volverá a la normalidad”, "si habrá un repunte del contagio" "qué dimensiones alcanzará la segunda oleada del virus, y si habrá una tercera ola”, y “después...". La preocupación cotidiana se ha convertido en la preocupación por programar, anticipar, prevenir. Los seres humanos tenemos una predisposición a adoptar decisiones tomando como referencia el futuro. Las coordenadas de espacio y de tiempo permiten la planificación y la motivación para la consecución de los objetivos fijados. Para ello, se parte de informaciones sobre situaciones y decisiones adoptadas anteriormente, que sirven de parámetro para anticipar cómo se van a desarrollar los acontecimientos y ajustar las elecciones futuras a lo acontecido en el pasado. A partir de lo observado, hay una capacidad de anticipar lo que aún no se ha llegado a observar. El grado de certeza en la capacidad de anticipar será mayor en unos casos que en otros, en los que habrá un mayor margen de duda, por tanto, de incerteza. ${ }^{16}$ La adopción estratégica de decisiones, intenta superar la probabilidad y alcanzar la certeza (jurídica) con la toma de decisiones.

El futuro se nos presenta con una paradoja. Por un lado, el presente es ya futuro (podría denominarse como presente-futuro); por otro lado, el futuro no puede comenzar (porque cuando va a comenzar, ya es presente) (sería el futuro-presente). No es fácil analizar la relación con el futuro porque no podemos describirlo, ya que no lo conocemos. No tenemos experiencia sobre el futuro. Sólo podemos construir el futuro, que es lo que hacemos continuamente desde nuestro presente. Lo que sabemos es desde nuestro conocimiento del pasado. Y el modelado de la sociedad - como sostiene De Giorgi- "Moral, religión, ideas políticas, ideologías, teorías, pero también pasiones, afectos, están ya disponibles y

\footnotetext{
${ }^{15}$ BORGES, J. L., "La doctrina de los ciclos", Historia de la eternidad, Alianza, Madrid, 1998, pp. 81-94. En la actualidad, Harari ha tomado el tiempo como guía para tres de sus más conocidas obras: un recorrido por nuestro pasado (Sapiens), una mirada a nuestro futuro (Homo Deus), y una indagación sobre nuestro presente (21 lecciones para el siglo XXI); también, vid. GOMEZ RAMOS, A., "La inmediatez de la crisis y la experiencia del tiempo", en DI LUCIANA, C. y VELASCO, G. (Compiladores), Normalidad de la crisis/crisis de la normalidad, Buenos Aires-Madrid, Katz Editores, 2012.

${ }^{16}$ MORENO CRUZ, D., "Introducción” a GOMETZ, G., La certeza jurídica como previsibilidad, trad. de Diego Moreno Cruz y Diego Dei Vecchi, Madrid, Barcelona, Buenos Aires, Sâo Paulo, Marcial Pons, 2012, p.11.
} 
utilizables para reducir el mundo a un formato accesible, para presentarlo en forma de alternativas, entre las cuales, orientarse no sea dramático", apoyándonos en las experiencias pasadas. Nos apoyamos en el pasado para llevar a cabo elecciones que afectan al futuro. Como explica De Giorgi, "sabemos solamente que también nuestro no-saber no nos sustrae a la necesidad de construir futuro". ${ }^{17}$

El Derecho está diseñado tanto para sancionar actos que han contravenido la legalidad como para anticiparse, para prever acciones que pudieran provocar un daño o una lesión de derechos a otro. Incluso la anticipación y prevención se refleja en algún principio, aunque limitado a áreas muy concretas -como el principio de precaución en el Derecho ambiental-. Esto lleva a preguntarse si se aprovecha el potencial que tiene el Derecho en cuanto que está revestido de esa dimensión de prospección y de prevención.

La relación del Derecho con el futuro presenta unas especificidades que conviene reseñar. Así, los juristas deciden a partir de los hechos en base al Derecho, y sus decisiones se adoptan considerando el futuro. Sin embargo, el lenguaje jurídico es el que puede dar lugar a un cierto grado de confusión ya que el lenguaje del Derecho, es decir, el lenguaje de los juristas es formulado como si incluyese en sí, una descripción de la realidad. Tanto en sus formas de la cualificación de sentido, como en las formas de la imputación, como en las formas de la decisión, su lenguaje se formula y se percibe como si estuviera describiendo la realidad. Pero se trata de una forma del deber ser y no del ser. De un deber ser que se hace manifiesto, sólo, si se viola la norma, como explicó Kelsen. Describe el futuro y prescribe para el futuro, pero acaba realizando una simbiosis entre lo que es y lo que debe ser. Los juristas no pueden renunciar a la idea del deber ser. "Los juristas tratan el deber ser ora como una dimensión de sentido, ora como una categoría, ora como una dimensión temporal que esconde en sí la unidad de la diferencia de pasado y futuro, ora como determinación que surge de la voluntad de todos los asociados de construirse certezas para su futuro y de confiar al Derecho su gestión.” 18

\footnotetext{
${ }^{17}$ DE GIORGI, R., “La justicialidad de los derechos humanos”, Revista Electrónica del Instituto de Investigaciones Jurídicas y Sociales Ambrosio Lucas Gioja, No. 12, 2014, pp. 124-139. https://dialnet.unirioja.es/servlet/articulo?codigo=7183866 también, vid. FERNANDES CAMPILONGO, C.; VEIGA DA ROCHA, J. E., FARIA, J.E.; PORTO MACEDO Jr. R., "E quando o futuro começar? Uma análise sobre o direito no pós-pandemia", JOTA - Opinião \& Análise, 19 agosto 2020: https://www.jota.info/opiniao-e-analise/artigos/e-quando-o-futurocomecar-19082020; FERNANDES CAMPILONGO, C.; VEIGA DA ROCHA, J.P., "Concorrência, sistema financeiro e futuro", Conjur, 14 Agosto 2020. https:/www.conjur.com.br/2020-ago-14/campilongo-rocha-concorrencia-sistema-financeiro-futuroOpinião
}

18 “"Los juristas] no derivan el derecho, entendido como deber ser, de los hechos, así como no derivan los hechos del derecho. Ellos argumentan. Construyen. Imputan. Fijan conexiones de sentido sobre la base de conexiones de sentido. Hacen inferencias, deducen. En realidad, ellos construyen lo que ellos usan como realidad. Y es esta la realidad de la realidad del derecho. Pero es esta realidad también el futuro, aquella realidad a la cual se da el nombre de futuro". DE GIORGI, R., "La justicialidad de los derechos humanos", cit., p.129. 
Lo problemático es que se busca en el Derecho una certeza que no puede ofrecer. No hay que confundir la seguridad jurídica, que constituye uno de los fines del Derecho y que sustenta el sistema de un Estado de Derecho, con el hecho de buscar en el Derecho, o bien la solución y refugio para todos los males y acontecimientos negativos que acecen en nuestras vidas o, por el contrario, la categoría para dirigir y focalizar todas las culpas por los hechos negativos. Hay que salir de esa polarización extrema de que, o bien esperamos el auxilio del Derecho, o bien, el Derecho es la causa de todos nuestros males.

Resulta necesario configurar una estrategia del vínculo con el futuro. No se está haciendo referencia aquí a planificar un futuro "de desescalada" (abrir o cerrar fábricas, abrir o cerrar el comercio o la hostelería). Hay que tratar el futuro con contingencia. Significa que una decisión que se adopte hoy, pueda ser revisada después.

\subsection{Reconstrucción de la alteridad}

La estrategia del vínculo con el futuro también significa construir situaciones y espacios de alteridad, inmunizar frente a la exclusión. El Covid-19 ha agudizado la situación de colectivos vulnerables (personas mayores, inmigrantes, personas con discapacidad, personas en centros penitenciarios, etc.) que impelen a dirigir la mirada hacia los Otros. En las relaciones socio-jurídicas y políticas actuales, asistimos a un cruce de corrientes éticas y filosóficas muy diversas. Por un lado, está la filosofía de la postmodernidad y del pensamiento débil, desconfiando de la relación con el Otro, que tiene a Bauman como uno de sus representantes más significativos. ${ }^{19}$ Por otro, está la ética de la otredad, en la línea de Levinas, con su defensa de la ética de la alteridad. ${ }^{20}$ De ahí que los vínculos sociales que para unos autores representan incertidumbre, para otros constituyen un armazón sobre el que se pueden construir vínculos sólidos.

Lo que diferencia a la sociedad actual de aquella de la Modernidad en su fase sólida, que buscaba ser duradera y resistente al cambio, es la creciente debilidad de los lazos sociales. Según Bauman, el cambio social entre la Modernidad y la postmodernidad hace florecer un mayor individualismo que conlleva una aptitud de competencia permanente, en detrimento de aptitudes solidarias, lo que provoca

\footnotetext{
${ }^{19}$ BAUMAN, Z., Amor líquido: acerca de la fragilidad de los vínculos humanos. Fondo de Cultura Económica de España, 2005.

${ }^{20}$ LÉVINAS, E., Totalidad e infinito, Salamanca, Sígueme, 2006; también, vid. LEVINAS, E., Entre nosotros. Ensayos para pensar en otro. Valencia, Pre-textos, 2001.La alteridad se da en un ámbito nuevo del ser y de la esencia, que consiste precisamente en un no-lugar (de nuevo, la categoría del espacio, ahora con otro sentido).
} 
una propensión al miedo a la caída social, y por lo tanto, produce una búsqueda constante de la seguridad. Nos recuerda los riesgos y angustias de vivir juntos y separados en nuestro moderno mundo líquido. En esta ocasión, se concentra en el amor y en el miedo a establecer relaciones duraderas, más allá de las meras conexiones. Nuestros contemporáneos, dice Bauman, desesperados al sentirse descartables, siempre ávidos de una "mano servicial", sin embargo, todo el tiempo desconfían del "estar relacionados", sobre todo si es "para siempre", ya que temen convertirse en una carga y desatar expectativas que no pueden ni desean soportar.

La cuestión del Otro y del nosotros ha sido objeto de construcciones de pensadores tan diversos como Sartre, con su teoría sobre la existencia del Otro y sobre la relación original entre las conciencias, ${ }^{21}$ o como Levinas y su ética de la alteridad. Frente a una búsqueda de la humanidad en el egocentrismo y en el aislacionismo, la corriente de pensamiento que impulsa la otredad, sostiene la identidad a través de la alteridad. La alteridad implica relación, comunicación, subjetividad, formando una sociedad en la responsabilidad del Yo para con el Otro; se manifiesta como "lo-otro-que-Yo". ${ }^{22}$ Tomando como referencia la primera posibilidad, "Yo respondo del Otro, porque me habla, demanda de mí una respuesta a su sufrimiento, a su dolor, a su menesterosidad, a su vulnerabilidad. El Yo es responsable del Otro, porque el Otro se da, y se deja ser reconocido en el huérfano y en la viuda, en el menesteroso, en el extranjero". ${ }^{23}$ Aquí no hay atisbo ni de individualismo ni de cosificación del Otro. Esa es la ética que se espera conseguir del Otro. Esa ética de la alteridad enlaza con el principio de solidaridad porque, implícitamente, ambos comparten el espíritu de la fraternidad y la oposición al individualismo narcisista. En tiempos del Covid-19, el individualismo y el solidarismo entran en una especie de confrontación mucho más acusada que en otras circunstancias.

La Modernidad -bien sea líquida o de otro tipo-, se ha venido construyendo a partir de la referencia al Otro. Pero en realidad, yo mismo soy Otro para ese Otro. Hasta ahora, la diferencia con el Otro hacía que se marcaran las diferencias con ese Otro (el inmigrante, el trabajador, el menor, el enfermo). A partir

\footnotetext{
21 SARTRE, J. P., El ser y la nada. Madrid, Alianza, 1984.

${ }^{22}$ Mediante la toma de conciencia de la alteridad del Otro, y de mi propia alteridad constitutiva, comienza un nuevo proyecto de relación interpersonal basado en el diálogo, el respeto, la tolerancia, y la aceptación de la diferencia -y no solo de la semejanza-. Me siento impelido (no llamado) "para-con-el-Otro", a mi pesar, contra mi voluntad". QUESADA TALAVERA, B., "Aproximación al concepto de 'alteridad' en Levinas. Propedéutica de una nueva ética como filosofía primera”. Investigaciones fenomenológicas, vol. monográfico 3: Fenomenología y política, 2011, pp.403-404

${ }^{23}$ QUESADA TALAVERA, B., “Aproximación al concepto de 'alteridad' en Levinas. Propedéutica de una nueva ética como filosofía primera”, Ibidem; También, vid. RICOEUR, P., Sí mismo como otro, Madrid, Siglo XXI, 1996.
} 
de ahora, cabe prever que habrá una mayor comprensión de la situación y de los problemas del Otro, en la medida en que se reclamará una recíproca comprensión (también del Otro con respecto a mí). La sociedad ha producido una excedencia de alteridades, muchas veces por la vulneración de derechos: pobres, periferias de las grandes urbes, marginales, inmigrantes, personas mayores, a quienes sí se los considera "los Otros". Es una excedencia de alteridades a las que la sociedad no consigue dar respuesta. Y no están inmunizados, no contra el Covid-19, sino contra la sospecha que los demás proyectan sobre ellos.

\subsection{Replanteamiento de la tridimensionalidad de la sociedad}

El dualismo entre orden y caos también encuentra, en esta era del Covid-19, una forma renovada de proyectarse. Porque qué sea el orden y qué sea el caos admite distintas interpretaciones dando lugar a utopías y distopías. El caos puede tener dos sentidos, el primero sería el de un estado de cosas completamente caótico, generalmente pos-apocalíptico, donde las estructuras sociales han desaparecido y el ser humano se ve condenado a vagar por una tierra yerma, guiado únicamente por sus instintos primarios. El segundo sentido del término, por el contrario, presenta un escenario de macro Estados totalitarios que hacen del orden su bien principal, basando sus fundamentos en teorías científicas extremas, y donde la razón, que justifica a quienes ejercen el poder, prima sobre las emociones. ${ }^{24}$ Esta segunda acepción del caos, permite entender la advertencia de Byung-Chul Han sobre "el regreso a la sociedad disciplinaria" y la aparente pasividad o fatalismo con el que se están asumiendo las consecuencias de ese "regreso" en las sociedades occidentales. Preocupa que, esa pasividad o fatalismo, pueda implicar una renuncia voluntaria a un marco de derechos no discutido hasta el momento en beneficio de una (aparentemente) cómoda disciplina. Y preocupa hasta dónde puede llegar esa renuncia voluntaria, si es que es posible ver voluntad en la pasividad. Tomando como referencia la segunda acepción de caos, se puede crear la confusión de que no es tal, sino que se trata de un orden y que, para que exista ese orden, debe imponerse una disciplina, garante de la seguridad de la población. ${ }^{25}$

\footnotetext{
${ }^{24}$ FOUCAULT, M., “El sujeto y el poder”, Revista Mexicana de Sociología, n50, Vol. 3, 1998, pp.3-20.

${ }^{25}$ En nuestra cultura, el miedo, el caos y el desorden, están ligados a la pérdida del status quo, es decir del poder. "Nos atemoriza el ser incapaces de controlar las variables de los cambios y tener que someternos al azar, ser simples espectadores del devenir. El miedo lo engendra no tener el control y reconocer que efectivamente no sabemos qué es el universo. Quienes ostentan el poder y son los dueños de los mecanismos que mantienen el orden, prefieren antes que perder el control, fortalecer las sujeciones, sin importar que los dispositivos de control atenten contra los derechos del ser humano, conduciéndonos a una distopía, entendida esta como la exacerbación del orden hasta el punto de anquilosar el mundo, viendo sus impulsores, en la inmovilidad, el modelo perfecto para mantener incongruentemente su continuidad". HAWKING, S., Historia del tiempo, Barcelona, RBA editores, 1993; también, vid. BALANDIER, G., El desorden, Barcelona, Gedisa, 1999.
} 
Todas estas consideraciones sobre caos y orden, unido a la vigilancia y a la consiguiente disciplina, han formado parte de esta pandemia. El virus ha supuesto una alteración de vidas y sistemas políticos y jurídicos, que ha habido que atajar recurriendo a imponer orden mediante la disciplina del control (vigilancia) para evitar la expansión del virus. Aunque se trate de una situación de emergencia y, por tanto, transitoria, sin embargo, ha demostrado con qué facilidad un orden que se consideraba firmemente asentado, resulta frágil y se ha puesto en cuestión.

Para comprender en sus debidos términos los cambios que ha experimentado la sociedad actual, puede recurrirse a las construcciones de Foucault acerca del biopoder. ${ }^{26}$ La tríade que, según Foucault, integraba la sociedad en la posmodernidad merece ser sometida a revisión para comprobar si ha sufrido modificaciones con motivo del Covid-19. La incertidumbre, como elemento que marca nuestro mundo, ya fue advertido por Foucault sin considerar que eso fuera tan terrible. Una vida incierta, insegura, impredecible e incontrolable es psicológicamente más soportable que la certeza moderna. El orden moderno ordena, clasifica, unifica, sirviéndose de posiciones dogmáticas y acaba resultando opresor. De ahí que sustente que, sólo en el caos postmoderno, puede sobrevivir la diferencia, la cual, además, permite mayores grados de libertad; el caos es antidogmático, antiautoritario, no opresor, ya que nadie se cree en posesión de la verdad absoluta, bandera de la libertad. Sin embargo, lo que no explica Foucault es cómo superar el relativismo al que acaba conduciendo ese caos postmoderno ni cómo paliar las incertidumbres que derivan del mismo. A juicio de Foucault, ley, luego disciplina, luego seguridad, es lo que se espera de las sociedades en situaciones de enfermedad (lepra, peste, viruela) con las que han tenido que lidiar a lo largo de la historia. ${ }^{27}$ Se cuestiona el concepto de orden con el que se ha trabajado en la Modernidad:

\footnotetext{
${ }^{26}$ El biopoder se desarrolla a través de dos formas que se entrecruzan. En primer lugar surge el poder disciplinario, que se centra en el individuo y en el cuerpo como máquina, y cuyos principales mecanismos son la vigilancia y el castigo. En segundo lugar, surge la biopolítica,que tiene por objeto la población y el cuerpo humano como especie biológica, y que actúa mediante controles y regulaciones. Espósito, con la finalidad de articular lo que no está articulado en la teoría foucaultiana, construye el "paradigma de inmunización", que permite la conservación de la vida, la conservatio vitae, su principal objeto de ejercicio de poder. La experiencia del Covid-19 ha sacudido las estructuras inmunitarias del Estado, de la propiedad y de la libertad, al menos en el capitalismo occidental. Cfr. ESPOSITO, R., "Biopolítica y coronavirus", La Repubblica (28 de febrero de 2020), trad. de Miquel Seguró. https://www.filco.es/biopolitica-y-coronavirus/

${ }^{27}$ En el curso Seguridad, territorio, población, dictado por Foucault entre enero y abril de 1978, en el Colegio de Francia, esboza lo que denomina una "historia de las tecnologías de seguridad", aplicadas a la sociedad occidental, a través del estudio de los mecanismos mediante los cuales, en el siglo XVIII, la especie humana ingresó en lo que el autor denomina "una estrategia general de poder". Para explicar los mecanismos de poder, se detiene en el sistema legal y en los mecanismos disciplinarios y dispositivos de seguridad. Para ello, recurre a un ejemplo como es el de la exclusión de los leprosos en la Edad Media (introduciendo una partición de tipo binario entre quienes eran leprosos y quienes no lo eran); los reglamentos de la peste con un fin distinto, como era el de cuadricular literalmente las regiones y ciudades dentro de las cuales había apestados, con normas que establecían cuándo y cómo podía salir la gente, horarios, qué tipo de alimentación, en definitiva, un sistema disciplinario); y la inoculación de la viruela (para saber cuántas personas eran víctimas, a qué edad, con qué efectos, que lesiones y qué mortalidad). En este último caso, el problema ya no es la exclusión como en la lepra, ni el de la cuarentena como en la peste, sino que el problema de las epidemias y las campañas para erradicarlas FOUCAULT, M., Seguridad, territorio y población. Curso en el Collège de France: 1977-1978, Buenos Aires, Fondo de Cultura Económica, 2006, pp.24-25
} 
se plantea si, en las sociedades, se ha pasado del orden a la seguridad, y si los sistemas públicos que se inventan para el bienestar de la población, no terminan oprimiéndola.

De esta forma, el triángulo problemático de seguridad-territorio-población, propio de las sociedades pre-industriales -que Foucault planteaba como marco de referencia de investigación- parece haber sido sustituido ahora por la tríade seguridad-población-gobierno, cuyo sentido es a la vez histórico y político, y que adquiere singular vigencia en el diagnóstico del presente. Una sociedad se levantaba sobre tres conceptos: población (los ciudadanos que ejercían sus derechos en libertad); territorio (espacio sobre el que se ejercía su soberanía); seguridad (una institución -Gobierno- que es la que ofrecía las condiciones de orden para el desarrollo de la vida en esa sociedad). Era una especie de contrato implícito. Sin embargo, a partir de la pandemia, esta tríade ha sufrido modificaciones: Seguridad - que se ha transformado en control y vigilancia, habiendo pasado a segundo plano la protección-; ${ }^{28}$ población (confinada, no en libertad); y territorio (cambiante porque, de ser abierto al cosmopolitismo y no tener límites como consecuencia de la globalización, ha pasado a cerrar fronteras y replegarse en los Estados nacionales"). Como en Foucault, la noción de gobierno emerge con fuerza, cuestionándose la gobernanza (su auctoritas no su potestas), y no tanto las medidas de seguridad.

La cultura occidental tiene miedo al desorden. La complejidad del mundo nos ha conducido a simplificar la realidad, a abstraer la naturaleza para hacerla cognoscible, y a recurrir a la dualidad o a sistemas binarios como una estructura de orden: Bien y mal; objetivo y subjetivo; arriba y abajo; revolucionario o inamovible. Los críticos de la Modernidad consideran este dualismo una trampa, pero para otros refleja una tendencia a ordenarlo todo que, aunque acabe chocando con la misma realidad, irregular y discontinua. Sin embargo, proporciona un asidero objetivo al que agarrarse, huyendo así del relativismo, de la subjetividad y de la variabilidad. Y tampoco está reñida con las revoluciones cuando ese orden se ha tergiversado, a pesar de que la revolución lleve al caos social. Esa mutación que podrá conllevar la sociedad (pos)pandémica, se confía en que sea para la búsqueda de un orden renovado, que aporte seguridad dentro de su ínsita flexibilidad.

\section{4. (Re)pensar el Derecho}

\footnotetext{
${ }^{28}$ En el pensamiento (pos)moderno la vigilancia y el control han sido conceptos claves. Vid. DELEUZE, G., "Posdata sobre las sociedades de control" en C. FERRER (Comp.), El lenguaje literario (Tomo II), Montevideo, Nordan, 1991; BAUMAN, Z. y LYON, D., Vigilancia líquida, Barcelona, Paidós, 2013.
} 
Como acertadamente explica el profesor Pérez Luño, “el filósofo del derecho no sólo tiene como cometido el análisis de cómo 'es' el derecho, sino también el de cómo 'debe ser". ${ }^{29}$ Esta preocupación se torna aún más imperativa a la hora de reflexionar sobre el Derecho en un escenario post-coronavirus, no sobre el Derecho que hasta ahora "era" sino el de "cómo debería ser" para el futuro.

Modernidad-Posmodernidad, incertidumbre-certeza, orden-caos, vigilancia-seguridad-control, libertad-seguridad, pasado-futuro, el yo-el Otro, globalización-desglobalización, ética de la alteridadindividualismo narcisista, son todos elementos presentes en una sociedad del riesgo y que permiten entender la polarización y fuerzas enfrentadas que suelen presentarse en los sistemas jurídicos. El virus ha incidido en el mundo del Derecho provocando una inflación de Decretos leyes y de Órdenes Ministeriales de desarrollo. ${ }^{30}$ Pero más allá de dar soluciones a un problema sanitario, ${ }^{31}$ y de la regulación ad hoc en todos los órdenes para gestionar la situación derivada de la pandemia, e incluso de los Anteproyectos de Ley para agilizar la Administración de Justicia, ${ }^{32}$ conviene plantearse si el Derecho está llamado a sufrir alguna reformulación para que sea capaz de dar respuesta, por un lado, a retos que aún no se habían logrado resolver y, por otra, a los desafíos que raíz de la pandemia se han tornado más evidentes. Es decir, se plantéa el interrogante sobre de qué modo debería configurarse el Derecho para ofrecer esa "inmunización” que la sociedad necesita. ${ }^{33}$ Seguidamente, formulamos algunas propuestas

${ }^{29}$ PÉREZ LUÑO, A. E., "La filosofía del derecho como tarea: cuestiones y trayectorias de investigación”, Anales de la Cátedra Francisco Suárez, $n^{\circ} 44,2010$, p.547. revistaseug.ugr.es > index.php > acfs > article > viewFile

${ }^{30}$ Algunos despachos jurídicos han procedido a editar textos recopilatorios de la normativa tan dispersa que ha provocado la pandemia. Un ejemplo es el de Uría Menéndez: "Compendio normativo de disposiciones aprobadas en relación con la crisis sanitaria del covid-19 (22 Mayo 2020)" y "Guía sobre cuestiones jurídicas clave relacionadas con la crisis sanitaria del covid-19 (1 Mayo 2020 )". https://www.uria.com/es/otros/covid-19

31 Vid. SERRA CRISTÓBAL, R., "Los riesgos del Covid-19 más allá de la salud”, alrevesyalderecho 12 abril 2020. http://blogs.infolibre.es/alrevesyalderecho/; también, SOLANES CORELLA, A., "Racismo, Xenofobia y COVID-19", alrevesyalderecho, 6 mayo 2020. http://blogs.infolibre.es/alrevesyalderecho/

32 Publicación del Real Decreto-ley 16/2020, de 28 de abril, de medidas procesales y organizativas para hacer frente al COVID-19 en el ámbito de la Administración de Justicia; Actualmente, el Misniterio de Justicia está ultimando el Anteproyecto de Ley de medidas procesales, tecnológicas y de implantación de medios de solución de diferencias. Este último, también incidirá en las formas de entender el Derecho, impulsando otros procedimientos de gestionar los conflictos mediante acuerdos, en un contexto de cooperación y colaboración entre las partes.

${ }^{33}$ Como acertadamente ha expuesto Roberto Esposito, una cierta dosis de inmunización es necesaria. Ningún cuerpo individual o colectivo podría vivir sin un sistema inmunitario. No existen comunidades históricas que no cuenten con alguna forma de inmunización, la primera de las cuales es el Derecho, sin el cual, los conflictos serían insostenibles. Ahora bien, el equilibrio entre comunidad e inmunidad (Derecho) es delicado, porque una intensificación de la inmunidad, en lugar de proteger a la colectividad, puede acabar negándola. ESPOSITO, R., “La prima immunizzazione è il diritto". Entrevista. L'Osservatore Romano, 04/05/2020.

https://www.vaticannews.va/it/osservatoreromano/news/2020-05/la-prima-immunizzazione-e-il-diritto.html. Cabe aquí también (re)pensar si este Derecho podría encajar en algunos de los parámetros del "Derecho dúctil" propuesto por Zagrebelsky. Cfr. ZAGREBELSKY, G., El Derecho dúctil. Ley, derechos, justicia, $11^{\mathrm{a}}$ ed., Madrid, Trotta, 1998. 
acerca de a qué debería de atender y dar respuesta (cómo "debería ser") ese Derecho en los tiempos postCovid:

-Un Derecho pronto a dar respuestas a la sociedad del riesgo: Una sociedad del riesgo como la actual demanda su correlativo Derecho. La sociedad del riesgo, a modo de etiquetado, agrupa todos los post (post-moderno, post-industrial, post-estructuralista), y engloba todos los posibles eventos que causarían alarma social (atentado terrorista, catástrofe natural, virus). En toda sociedad de riesgo se necesita un enemigo que puede ser, tanto la tecnología (después una tecnología más moderna reemplazará a la vieja; más tarde se verá que la anterior era mejor, y así sucesivamente) como un virus (se encontrará la vacuna pero la cepa del virus mutará y podrá volver a ser la causa de graves contagios y así sucesivamente; habrá ciudadanos que se nieguen a que se les administre la vacuna, por lo que el peligro de contagio seguirá). Resulta imposible resolver la falta de unidad de la diferencia, se trabaja en un dualismo permanente, por lo que la búsqueda de la seguridad se convierte en una retórica. ¿Es segura la seguridad? ¿Qué seguridad es segura? Por ello, alrededor de la seguridad se construyen estrategias y mecanismos de seguridad. Pero cuanto más aumentan los controles para garantizar la seguridad, a su vez también se incrementan los riesgos.

- Un Derecho vigilante de la interpretación que se haga del propio Derecho: Hay que replantearse la interpretación del Derecho. En tiempos de grandes riesgos e incertidumbres -como en el pandémicoha resultado evidente que las normas jurídicas no son lingüísticamente unívocas, y que tampoco son algo objetivo que se encuentra en el texto de la ley sino el resultado de una contextualización. ${ }^{34}$ La realidad en tiempos de pandemia se ha vuelto cada vez más compleja (confinamientos selectivos según índice de contagios y rebrotes en municipios con la consiguiente afectación/suspensión de derechos a partir de confinamientos perimetrales), lo que ha supuesto que los tribunales hayan dictado decisiones contradictorias (en unos casos avalando las medidas de confinamiento y, en otros, suspendiendo tales medidas). Ha habido que adaptarse a una situación de incertidumbre. La interpretación del Derecho, y más en situaciones de incerteza como la actual, adquiere mayor protagonismo y no puede dejarse descansar en una mera decisión política (confinamiento / proporcionalidad de medidas sanitarias, control y vigilancia de la libertad individual / derechos fundamentales).

\footnotetext{
${ }^{34}$ FARIA, J.E. y PORTO MACEDO JUNIOR, R., “A pandemia e a interpretação do Direito - Política - Estadão”, Blog Fausto Macedo, 12 ago. 2020. https://politica.estadao.com.br/blogs/fausto-macedo/a-pandemia-e-a-interpretacao-do-direito/
} 
- Un Derecho atento a la aparición de un nuevo concepto jurídico indeterminado, como es la "nueva normalidad"35: bajo ese término se han establecido unos nuevos usos sociales y nuevas normas. La confianza ciega en que los principios puedan resolver todo, con la mera invocación de la dignidad, la proporcionalidad, la igualdad y la justicia hace que cobre más fuerza la idea de que la política se proyecta sobre la justicia. Esta situación ha supuesto una inseguridad jurídica que debilita los pilares del Estado de Derecho y que puede conllevar un retroceso para nuestro Derecho. E1 Derecho no es, ni un conjunto de normas totalmente predeterminado, ni un juego al albur de las decisiones del poder. Esa "nueva normalidad", sociológica y económica, se erige como una fuente de normatividad, la cual no solo exige sino que, a su vez, también constituye en sí misma nuevos criterios de interpretación. Son normas que no se pueden discutir en un contexto de sociedad vigilada y paternalista, en la que todo se decide por el bien de los ciudadanos y de su salud. Pero la conciliación de nuevas necesidades y las consiguientes nuevas respuestas, no significa que esa renovada adaptabilidad pueda mudar sin más los pilares del estado democrático de Derecho, escudándose en un pretendido “derecho de excepcionalidad”.

-Un Derecho que incorpore los valores realmente necesarios para garantizar una vida digna: La búsqueda de la seguridad y de la paz social hace recurrir a los valores como si ofrecieran referentes de cómo comportarse. Pero hay qué discernir a qué valores se recurre, ya que muchos de ellos no nos dan la orientación que se buscaba, y menos para una construcción del Derecho. Así, los valores económicos y financieros se miden por el Producto Interior Bruto -PIB- pero, este índice de medición, no puede calcular la calidad de vida ni la duración de la vida. Son valores sin reflejo en los usuales medidores e índices económicos y políticos. Posiblemente, la era post-Covid-19 desembocará en un cambio de valores. Hay que recuperar la producción de una sociedad del otro, y este propósito requiere a su vez de otro Derecho. Así se podrán abrir las puertas, siempre con incertidumbre, pero con la posibilidad de escoger entre varias posibilidades. La sociedad inventó el positivismo jurídico para protegerla de esos daños -aunque se ha revelado claramente insuficiente- y ahora, sistema jurídico y sociedad, dependen de un código de Derecho. Hay que reconstruir la inmunización que puede ofrecer el Derecho: sin límites territoriales; universalidad de bienes; recuperación de los cuerpos, visibilizando al excluido y a los vulnerables.

\footnotetext{
${ }^{35}$ Los análisis de Foucault sobre la crisis de racionalidad jurídica liberal constituyen una perspectiva desde la que analizar el surgimiento de nuevas formas de racionalidad jurídica, basadas en los conceptos de "norma" y "normalidad".
} 
-Un Derecho que escape a la trampa de esa lógica de la alternatividad y de la circularidad: El pasado no da estabilidad. El problema se refiere al futuro como potencial amenaza. La incorporación del futuro y las razones del Derecho no son las de la ciencia ni las de la Economía. Se necesita un nuevo orden. La racionalidad universal occidental se ha venido apoyando en un dualismo alternativo de valores: ricos/pobres, señores/esclavos, desarrollo/subdesarrollo. Hay que salir del bucle perverso de la circularidad, pero sin renunciar a las aportaciones meritorias de la Modernidad. De lo contrario, se continuará con un Derecho que permite una sociedad que, a su vez, produce exclusión (porque produce inclusión). Eso sí, no se trata de salir de esas dicotomías sin más, sino sólo cuando haya una alternativa valiosa.

- Un Derecho que incentive y refuerce la construcción de verdaderos vínculos con el Otro: Al futuro sólo se puede llegar mediante la construcción de vínculos, para hacer posible el mantenimiento de las propias expectativas, aunque al final no se cumplan. El riesgo es el correlato del saber y del no-saber. No se puede burlar el riesgo o intentar neutralizarlo mediante un Derecho predictivo que únicamente ofrece resultados matemático-estadísticos, pero que no puede ofrecer certezas. La comunicación social resulta indispensable para gestionar los conflictos, y aquí se incardina la ética de la alteridad y la ética del cuidado, que deberá combinarse con la ética de la responsabilidad (pero sin que se la utilice torticeramente: cada uno debe ser responsable de sus actos, "si te extralimitas en el plan de desescalada, serás responsable de tu enfermedad y de la de los demás”).

- Un Derecho que se extienda a la regulación de la sociedad del contagio: El Derecho debe enfrentarse, ya no sólo a una sociedad del riesgo y del miedo, sino a una sociedad del contagio. Aislamiento, distanciamiento social, sospecha con respecto al estado de salud del Otro, discriminación sobre quién es el insolidario y el desobediente que no lleva la mascarilla, que participar en actividades de ocio sin respetar la distancia social, ese riesgo-miedo al contagio construye una narrativa que, precisamente, no favorece ni la otredad ni la empatía. Esta sociedad del contagio presenta unas paradojas: por un lado, se refuerza la individualidad ya que cada uno busca la seguridad aislándose en su casa, pero por otro lado, se reinventan formas de convivencia con un horizonte del cuidado y del reconocimiento de la alteridad. La responsabilidad individual ha dado una respuesta satisfactoria en una situación inédita. El potencial contagiante acaba desembocando una reformulación semántica de la alteridad con el Otro. Pero a la vez, las llamadas a la autoresponsabilidad no cesan con la finalidad de atajar conductas 
insolidarias. El Covid-19 nos expone a unos mandatos que cuestionan nuestro espíritu de la racionalidad y de la Modernidad.

- Un Derecho capaz tanto de regular y dar respuesta a la globalización como a la desglobalización: La globalización también ha resultado gravemente afectada por la pandemia y los retro-globalistas han alzado su voz. Un pequeño virus fue suficiente para causar caos en los mercados financieros y en la vida cotidiana. Pero el propio virus es también una consecuencia de la globalización. El proceso de globalización, en sus diversas esferas, se había construido sobre la premisa de la libre circulación de mercancías, personas e ideas, en un flujo constante de espacios abiertos. Pero ahora, ese mismo proceso de globalización es considerado el principal culpable de que el virus se haya extendido. ${ }^{36}$ Ello inclina a pensar que, por un lado, habrá un repliegue hacia los Estados nacionales, pero, por otra parte, se buscarán alianzas comunes. ${ }^{37}$ Globalización y desglobalización están llamadas a convivir, confluyendo como fuerzas centrífugas y centrípetas que podrán implicar fricciones, a las que el Derecho deberá atender.

Asimismo, el papel de la Unión Europea ante las crisis deberá definirse, así como su posición en el escenario global. La Unión Europea ha tenido ocasión de poner de manifiesto su solidaridad con los países más afectados por la pandemia (como Italia y España). Pero también ha tenido ocasión de sacar a la luz acciones competitivas en una desenfrenada carrera por la obtención de medicamentos y material sanitario primero, y por las vacunas después. Habrá que estar especialmente vigilantes para prevenir y ataajra prácticas de abuso y corrupción en la gestión de fondos europeos procedentes del Mecanismo de Recuperación.

36 "La idea es que haya un retorno de la supremacía política sobre las finanzas [...]. Habrá un cambio total del paradigma político”. GERVASONI, M. y OCONE, C., “Coronavirus. ¿El fin de la globalización?”

https://mundo.sputniknews.com/entrevistas/202003271090921040-coronavirus-el-fin-de-la-globalizacion/

${ }^{37}$ El riesgo no puede ser juridificado, no se puede resolver con más o menos Derecho sino con la técnica: prevenir e impedir antes de que se produzca o bien, intervenir después de que el evento dañoso se haya verificado. Pero hay una ausencia de garantías, encerrada en una especie de circularidad. Cuando se diseñan garantías, surgen nuevas problemáticas. El propio Ferrajoli, defensor de la teoría garantista de los derechos, busca nuevos asideros a los que aferrarse, tales como un "constitucionalismo planetario", en los términos en los que fue propuesto, en la denominada escuela "constituyente de la Tierra", en febrero de 2020, en Roma. Problemas globales exigen respuestas globales. La propuesta de Ferrajoli encajaría en la línea de las alianzas internacionales que, auguramos, van a ser imprescindibles en los próximos años, evitando fragmentaciones y medidas aisladas que nada aportan y que sólo implican debilidad. FERRAJOLI, L., "Lo que nos enseña el coronavirus. Por un constitucionalismo planetario", Extramuros. Blog Oficial de Palestra Editores e Instituto Palestra, trad. de Pedro P. Grández. (18 Marzo 2020).

https://palestraextramuros.blogspot.com/2020/03/lo-que-nos-ensena-el-coronavirus.html;

también, vid. BAUMAN, Z., La globalización: consecuencias humanas, Buenos Aires, Fondo de Cultura Económica, 2006. 


\section{Reflexiones finales. A propósito de una filosofía jurídica del post- virus}

De la era pandémica, no debe hacerse una lectura apocalíptica ni tampoco bucólica, como si a resultas de la misma, fuera a emerger repentinamente una nueva sociedad fraterna o un individualismo exacerbado, encerrado en su segura torre de marfil. Utopías y distopías deben desterrarse. Las situaciones de catástrofes naturales -como la del virus- suelen ir acompañadas de reflexiones y valoraciones de diversa índole que incitan a (re)pensar el Derecho, tal y como se está haciendo a partir del Covid-19. De ahí que, la filosofía jurídica pueda ser una de las disciplinas idóneas para interrogarse y reflexionar sobre cómo debería ser el escenario post-pandémico:

- El que cada cierto tiempo se quiebren los paradigmas ha sido una constante a lo largo de la historia de la filosofía del Derecho, y forma parte de la propia evolución de la reflexión filosófica que se hace sobre los acontecimientos (ruptura / continuidad). La pandemia ha afectado a temas basilares del Derecho, provocando una alteración de cuestiones jurídicas fundamentales. Las crisis pueden constituir una ocasión para avanzar y mejorar la ciencia jurídica, con la consiguiente renovación de paradigmas, pero en este caso, lo que está primando es una alteración de construcciones jurídicas dogmáticas sólidamente construidas, con la posibilidad de que se debiliten derechos fuertemente asentados en un Estado democrático de Derecho, por lo que hay que estar vigilantes con respecto a los efectos perversos que la pandemia pueda provocar en el ámbito constitucional en general, y en el Derecho en particular.

- Se han recuperado postulados básicos que habían sido olvidados, tales como una mayor concienciación de la vulnerabilidad humana y de la fragilidad de las estructuras (económicas, sanitarias, sociales); se ha tomado conciencia de que el interés individual no puede desligarse del colectivo; que la responsabilidad y la autonomía individual es compatible con estar distantes del "Otro" (Las medidas de distanciamiento social que deberán seguir vigentes un tiempo, supondrán una distancia física pero no equivale a desentenderse de los demás); se ha redescubierto la solidaridad, la interdependencia y la cooperación. Pero conviviendo con esos valores, también ha emergido la desconfianza, la insolidaridad, y la búsqueda de la propia seguridad, por encima de cualquier otro fin común, mostrando la cara menos amable del ser humano.

- La crisis y el miedo han instalado ideas como que el autoritarismo y el poder concentrado son buenas recetas para frenar la expansión del virus. Pero una sociedad libre y evolucionada debería pensar en generar soluciones y tomar conciencia, a partir del acceso a una información veraz y a una mejora de 
las libertades. Si se desea seguir siendo sociedades libres, habrá que hacerlo de la mano de la tecnología y la transparencia. Ya no queda lugar para procesos opacos en la toma de decisiones. Los ciudadanos han dado un ejemplo de responsabilidad y eso debe tener como respuesta, no un aumento de las restricciones, sino una mejora de las libertades. Ello será una prueba de que se confía en la respuesta de los ciudadanos. Autonomía, auto-responsabilidad, confianza, constituyen unos pilares que conviene que se incorporen a los parámetros de ese renovado Derecho post-Covid.

- El Derecho está llamado a cuidar las alteridades, especialmente en un tiempo en el que van a aumentar significativamente las personas y grupos en situación de vulnerabilidad. Ello implica que la vertiente social de los derechos humanos deberá ser objeto de especial atención. Y no se trata sólo de consolidar derechos sociales sino de que recupere la corporeidad, la visibilidad de esos otros tradicionalmente excluidos, invisibilizados muchas veces, y que ahora urge especialmente recuperar. Un Derecho que inmunice frente a la exclusión y la desigualdad -la brecha digital en el ámbito educativo ha sido una muestra-. Si la gestión de la pandemia no es eficaz, objetores, desobedientes y protestas sociales, serán la cara visible de las voces que no se han escuchado.

- El Derecho se verá cada vez más expuesto a tener que lidiar con situaciones binarias (salud/ Economía; salud pública/libertad de movimiento; salud/privacidad; derecho a la información/Gobierno paternalista-controlador) que incidirán de forma directa en el ejercicio de derechos fundamentales, lo que exigirá una cuidadosa ponderación por parte de los operadores jurídicos.

En definitiva, una sociedad post-Covid exigirá un Derecho capaz de ofrecer respuestas y seguridad jurídica en el incierto tiempo (pos)pandémico. 


\section{Referencias bibliográficas}

AA. VV. El Cronista del Estado Social y Democrático de Derecho. Coronavirus ... y otros problemas, $\mathrm{n}^{\circ}$. 86-87 Marzo-abril 2020. www.elcronista.es > El-Cronista-número-86-87-Coronavirus

AGAMBEN, G., "The Invention of an Epidemic", European Jornal of Pshicoanlysis (Publicado en Italia en Quodlibet, https://www.quodlibet.it/giorgio-agamben-l-invenzione-di-un-epidemia $) \quad(26 \quad$ Febrero $\quad 2020) \quad$ https://www.journalpsychoanalysis.eu/coronavirus-and-philosophers/

BALANDIER, G., El desorden, Barcelona, Gedisa, 1999.

BAUMAN, Z., Amor líquido: acerca de la fragilidad de los vínculos humanos. Fondo de Cultura Económica de España, 2005.

BAUMAN, Z. y LYON, D., Vigilancia líquida, Barcelona, Paidós, 2013.

BECK, U., La sociedad del riesgo. Hacia una nueva modernidad, Barcelona, Paidós, 2006.

BORGES, J.L., "La doctrina de los ciclos", Historia de la eternidad, Alianza, Madrid, 1998, pp. 81-94.

CITTON, Y. y RASMI, J., Générations collapsonautes. Naviguer par temps d'effondrement, Seuil, 2020.

DAVIS, M., “COVID-19: el monstruo llama a la puerta", trad. de Viento Sur, (13/03/2020).

https://vientosur.info/spip.php?article15712

DE GIORGI, R., Direito, Democracia e Risco: vínculos com o futuro, Porto Alegre, Sergio Antonio Fabris Editor, 1998.

DE GIORGI, R., "La justicialidad de los derechos humanos", Revista Electrónica del Instituto de Investigaciones Jurídicas y Sociales Ambrosio Lucas Gioja, No. 12, 2014, pp. 124-139. https://ialnet.unirioja.es/servlet/articulo?codigo=7183866

DELEUZE, G., "Posdata sobre las sociedades de control" en C. FERRER (Comp.), El lenguaje literario (Tomo II). Montevideo, Nordan, 1991.

DE LOS RÍOS, I., "Mórbida crisis, débil gobierno: Aristóteles y la estrategia del náufrago", en Di Luciana, C. y Velasco, G. (Compiladores), Normalidad de la crisis/crisis de la normalidad, Buenos Aires-Madrid, Katz Editores, 2012, pp.13-28.

ESPOSITO, R., “La prima immunizzazione è il diritto”. Entrevista. L'Osservatore Romano, 04/05/2020.

https://www.vaticannews.va/it/osservatoreromano/news/2020-05/la-prima-immunizzazione-e-il-diritto.html

ESPOSITO, R., "Biopolítica y coronavirus", La Repubblica (28 de febrero de 2020), Traducción: Miquel Seguró. https://www.filco.es/biopolitica-y-coronavirus/

FARIA, J. E. y PORTO MACEDO JUNIOR, R., “A pandemia e a interpretação do Direito - Política - Estadão”, Blog Fausto Macedo, 12 ago. 2020. https://politica.estadao.com.br/blogs/fausto-macedo/a-pandemia-e-a-interpretacao-do-direito/

FERNANDES CAMPILONGO, C.; VEIGA DA ROCHA, J. E., FARIA, J.E.; PORTO MACEDO Jr. R., "E quando o futuro começar? Uma análise sobre o direito no pós-pandemia", JOTA - Opinião \& Análise, 19 Agosto 2020. https://www.jota.info/opiniao-e-analise/artigos/e-quando-o-futuro-comecar-19082020

FERNANDES CAMPILONGO, C.; VEIGA DA ROCHA, J.P., "Concorrência, sistema financeiro e futuro", Conjur, 14 Agosto 2020. https://www.conjur.com.br/2020-ago-14/campilongo-rocha-concorrencia-sistema-financeiro-futuroOpinião

FERRAJOLI, L., "Lo que nos enseña el coronavirus. Por un constitucionalismo planetario", Extramuros. Blog Oficial de Palestra Editores e Instituto Palestra, trad. de Pedro P. Grández. (18 Marzo 2020).

https://palestraextramuros.blogspot.com/2020/03/lo-que-nos-ensena-el-coronavirus.html

FOUCAULT, M., "El sujeto y el poder”, Revista Mexicana de Sociología, n’.50, vol. 3, 1998, pp.3-20.

FOUCAUlT, M., Seguridad, territorio y población. Curso en el Collège de France: 1977-1978. Buenos Aires, Fondo de Cultura Económica, 2006. 
GERVASONI, M. y OCONE, C., "Coronavirus. ¿El fin de la globalización?”

https://mundo.sputniknews.com/entrevistas/202003271090921040-coronavirus-el-fin-de-la-globalizacion/

GÓMEZ RAMOS, A., "La inmediatez de la crisis y la experiencia del tiempo", en DI LUCIANA, C. y VELASCO, G. (Compiladores), Normalidad de la crisis/crisis de la normalidad, Buenos Aires-Madrid, Katz Editores, 2012.

HAN, B. Ch., Sociedad del cansancio, trad. de Arantzatzu Saratxaga Arregi, $2^{\mathrm{a}}$ ed., Barcelona, Herder Editorial, 2017.

HAN, B.Ch., "Entrevista", trad. de Alberto Ciria Madrid, Diario El País (22 Marzo 2020). https://elpais.com/ideas/2020-0321/la-emergencia-viral-y-el-mundo-de-manana-byung-chul-han-el-filosofo-surcoreano-que-piensa-desde-berlin.html

HARARI, Y. N., "Yuval Harari: El mundo después del coronavirus", Diario La Vanguardia (05.04.2020) (“The wordl after coronavirus", Financial Times, trad. de Juan Gabriel López Guix.

https://www.lavanguardia.com/internacional/20200405/48285133216/yuval-harari-mundo-despues-coronavirus.html

HAWKING, S., Historia del tiempo, Barcelona, RBA editores, 1993.

HARVEY, D., “Anti-Capitalist Politics in the Time of COVID-19” (19 marzo 2020; revisado 22 marzo 2020). https://davidharvey.org/2020/03/anti-capitalist-politics-in-the-time-of-covid-19/

IMBERT, N., "COVID 19 - 10 propuestas para pueblos y territorios más resilientes", Actualidad Jurídica Ambiental, n. 100, Sección "Comentarios" (6 Abril 2020).

INNERARITY, D. Una teoría de la democracia compleja. Gobernar en el siglo XXI, Barcelona, Galaxia Gutenberg, 2020.

INNERARITY, D., Pandemocracia. Una filosofia de la crisis del coronavirus, Galaxia de Gutenberg, 2020.

KLEIN, N., La doctrina del shock. El auge del capitalismo del desastre, trad. de Isabel Fuentes García; Albino Santos Mosquera y Remedios Diéguez Diéguez, Ed. Booket, 2007.

KLEIN, N., "Coronavirus Is the Perfect Disaster for 'Disaster Capitalism"”

https://www.vice.com/en_us/article/5dmqyk/naomi-klein-interview-on-coronavirus-and-disaster-capitalism-shock-doctrine

LARIGUET, G., "El coronavirus: miniaturas filosóficas" (3 abril, 2020) Redacción La Tinta https://latinta.com.ar/2020/04/coronavirus-filosofia/

LATOUR, B., "Imaginer les gestes-barrières contre le retour à la production d'avant-crise", AOC, (30 Marzo 2020). https://aoc.media/opinion/2020/03/29/imaginer-les-gestes-barrieres-contre-le-retour-a-la-production-davant-crise/

LEVINAS, E., Entre nosotros. Ensayos para pensar en otro. Valencia, Pre-textos, 2001.

LÉVINAS, E., Totalidad e infinito, Salamanca, Sígueme, 2006.

LUHMANN, N., [1991] Sociología del riesgo, México, Universidad Iberoamericana, Triana Editores, 1998.

MORENO CRUZ, D., "Introducción” a GOMETZ, G., La certeza jurídica como previsibilidad, trad. de Diego Moreno Cruz y Diego Dei Vecchi, Madrid, Barcelona, Buenos Aires, Sao Paulo, Marcial Pons, 2012.

PÉREZ LUÑO, A. E., "La filosofía del derecho como tarea: cuestiones y trayectorias de investigación", Anales de la Cátedra Francisco Suárez, no 44, 2010, pp.547-570. revistaseug.ugr.es > index.php > acfs > article > viewFile

QUESADA TALAVERA, B.A., “Aproximación al concepto de 'alteridad' en Lévinas. Propedéutica de una nueva ética como filosofía primera”, Investigaciones Fenomenológicas, vol. monográfico 3: Fenomenología y política, 2011, pp.393-405.

RICOEUR, P., Sí mismo como otro, Madrid, Siglo XXI, 1996.

RODRÍGUEZ, P., "Un debate con Giorgio Agamben, Slavoj Zizek, Byung Chul-Han, Markus Gabriel y Yuval Harari. Los intelectuales y los lugares comunes ante el coronavirus", Diario El Pais (08.04.2020). https://www.pagina12.com.ar/258063los-intelectuales-y-los-lugares-comunes-ante-el-coronavirus 
SARTRE, J. P., El ser y la nada. Madrid, Alianza, 1984.

SERRA CRISTÓBAL, R., "Los riesgos del Covid-19 más allá de la salud”, alrevesyalderecho, 12 abril 2020. http://blogs.infolibre.es/alrevesyalderecho/

SOLANES CORELLA, A., "Racismo, Xenofobia y COVID-19", alrevesyalderecho, 6 mayo 2020. http://blogs.infolibre.es/alrevesyalderecho/

URÍA \& MENÉNDEZ. Compendio normativo de disposiciones aprobadas en relación con la crisis sanitaria del covid-19 (22 Mayo 2020) y Guía sobre cuestiones jurídicas clave relacionadas con la crisis sanitaria del covid-19 (1 Mayo 2020). https://www.uria.com/es/otros/covid-19

ZAGREBELSKY, G., El Derecho dúctil. Ley, derechos, justicia, 11 1ª ed., Madrid, Trotta, 1998.

ZIZEK, S., "El coronavirus es un golpe al capitalismo a lo 'Kill Bill' que podría reinventar el comunismo", Russia Today, (29 feb 2020). https://actualidad.rt.com/actualidad/344511-slavoj-zizek-coronavirus-golpe-capitalismo-kill-bill-reinventarcomunismo

ŽIŽEK, S., PANDEMIC!COVID-19 Shakes the world, OR/Books, 2020. 